\title{
Observation of a mesospheric front in a thermal-doppler duct over King George Island, Antarctica
}

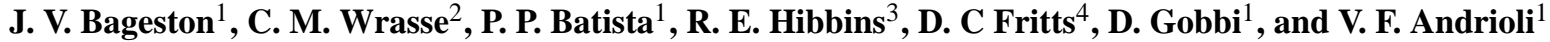 \\ ${ }^{1}$ Instituto Nacional de Pesquisas Espaciais (INPE), São José dos Campos, Brazil \\ ${ }^{2}$ Vale Soluções em Energia (VSE), São José dos Campos, Brazil \\ ${ }^{3}$ British Antarctic Survey (BAS), Cambridge, UK, and Norwegian University of Science and Technology (NTNU), \\ Trondheim, Norway \\ ${ }^{4}$ Colorado Research Associates (CoRA), Boulder, USA
}

Received: 6 May 2011 - Published in Atmos. Chem. Phys. Discuss.: 31 May 2011

Revised: 11 November 2011 - Accepted: 22 November 2011 - Published: 7 December 2011

Abstract. A mesospheric front was observed with an allsky airglow imager on the night of 9-10 July 2007 at Ferraz Station $\left(62^{\circ} \mathrm{S}, 58^{\circ} \mathrm{W}\right)$, located on King George island on the Antarctic Peninsula. The observed wave propagated from southwest to northeast with a well defined wave front and a series of crests behind the main front. The wave parameters were obtained via a 2-D Fourier transform of the imager data providing a horizontal wavelength of $33 \mathrm{~km}$, an observed period of $6 \mathrm{~min}$, and a horizontal phase speed of $92 \mathrm{~m} \mathrm{~s}^{-1}$. Simultaneous mesospheric winds were measured with a medium frequency (MF) radar at Rothera Station $\left(68^{\circ} \mathrm{S}, 68^{\circ} \mathrm{W}\right)$ and temperature profiles were obtained from the SABER instrument on the TIMED satellite. These wind and temperature profiles were used to estimate the propagation environment of the wave event. A wavelet technique was applied to the wind in the plane of wave propagation at the $\mathrm{OH}$ emission height spanning three days centered on the front event to define the dominant periodicities. Results revealed a dominance of near-inertial periods, and semi-diurnal and terdiurnal tides suggesting that the ducting structure enabling mesospheric front propagation occurred on large spatial scales. The observed tidal motions were used to reconstruct the winds employing a least-squares method, which were then compared to the observed ducting environment. Results suggest an important contribution of largescale winds to the ducting structure, but with buoyancy frequency variations in the vertical also expected to be important. These results allow us to conclude that the wave front event was supported by a duct including contributions from both winds and temperature.

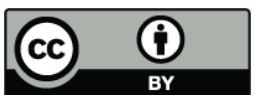

Correspondence to: J. V. Bageston (bageston@gmail.com)

\section{Introduction}

According to the definitions currently accepted by the scientific community, mesospheric front is a type of gravity wave which presents a frontal airglow emission enhancement or depletion that can be followed by a series of wave crests phase-locked to the leading front (Brown et al., 2004; Smith et al., 2005). These kind of frontal events are subclassified mainly between wall and bore. However, fronts that do not satisfy all the criteria of a bore or wall (Brown et al., 2004), but present analogous characteristics to these fronts - including a extended frontal pattern and ducting conditions - still can be classified as a mesospheric front, following the criteria listed by Brown et al. (2004).

Mesospheric front events have been extensively reported at low and mid latitudes (Taylor et al., 1995; Smith et al., 2003; Medeiros et al., 2005; Fechine et al., 2005). Taylor et al. (1995) described a spectacular bore event observed in four mesospheric nightglow emissions at Hawaii $\left(20.8^{\circ} \mathrm{N}\right)$ during the ALOHA-93 campaign. Intensity measurements showed that the front was characterized by a sudden increase in the $\mathrm{OH}$ brightness and a concurrent decrease in the OI emission. Smith et al. (2003) reported a large-scale, long-duration mesospheric bore over the southern US which was visible to the naked eye. Medeiros et al. (2005) and Fechine et al. (2005) have reported a large number of mesospheric bore or "front" events ( $>60)$ over northeastern Brazilian $\left(7^{\circ} \mathrm{S}\right) \mathrm{sec}-$ tor over a period of two years.

In contrast, bores or other front events are relatively uncommon events at Antarctic latitudes. Nielsen et al. (2006) observed five potential bores in four winter seasons, with only one clear event. That event was seen in airglow images from Halley Station $\left(75.5^{\circ} \mathrm{S}\right)$, Antarctica, with responses in three different airglow layers $\left(\mathrm{OH}, \mathrm{Na}\right.$, and $\left.\mathrm{O}_{2}\right)$, persisted for $\sim 3 \mathrm{~h}$, and exhibited a trailing wave crests behind the main

Published by Copernicus Publications on behalf of the European Geosciences Union. 
front, with an increase in the number of wave crests estimated at $\sim 6.6 \mathrm{crests}^{-1}$. The bore characteristics in this case were determined using a standard 2-D spectral analysis. The observed and intrinsic wave parameters were obtained for the three airglow layers. Because they did not have information about the temperature structure above Halley Station, they could neither infer the duct structure in which the bore was propagating nor identify the presence of inversion layers. Stockwell et al. (2006) applied a S-Transform analysis to the same event reported by Nielsen et al. (2006) in order to investigate the dynamical properties of the bore. They were able to infer the bore parameters (horizontal wavelength, observed horizontal phase speed, and period) and also described its evolution as it propagated. They observed that the horizontal wavelength and horizontal phase speed decreased, and the bore amplitude increased, as the bore evolved.

More recently, Stockwell et al. (2011) analized the vertical wavenumber squared $\left(\mathrm{m}^{2}\right)$ associated to the bore event reported by Nielsen et al. (2006), using the observed wave parameters, hourly wind measurements and MSIS model temperature. As they used the S-Transform to acess the bore parameters at distinct times, in the beginning of the observations they identified a free propagating region below $78 \mathrm{~km}$ and a evanescent region above this height. Three hours later they observed a pure evanescent region in the airglow region $(80-95 \mathrm{~km})$. In synthesis, in the work of Stockwell et al. (2011) no signal of a possible Doppler duct has been observed, and the existence of thermal duct could not be assessed because of the lack of observed temperature data. Also, Stockwell et al. (2011) estimated the duct depth and its variability while the bore was propagating and as the bore packet evolved the bore duct collapsed. This result was associated with the deceleration of the group velocity, the amplitude attenuation and the dissipation of the bore event.

In our observations at Ferraz Station during 2007, more than 230 gravity wave events were observed (Bageston et al., 2009). The report of only two wave front events (wall event reported by Bageston et al. (2011) and the present study), among a large number of gravity wave events, confirms the low occurrence rate of bores at high southern latitudes compared to lower latitudes (Fechine et al., 2005, 2009). The event reported here could not be classified as a mesospheric bore according to the criteria used in the literature (Dewan and Picard, 1998; Smith et al., 2003; Brown et al., 2004; Smith et al., 2005). The present observation is comprised by a mesospheric front having a sharp "front" that extended across the entire all-sky image, with a series of crests following the front and an observed phase speed of $92 \mathrm{~m} \mathrm{~s}^{-1}$. However, this front did not presented any kind of step function and we were not able to observe the wave front at different airglow layers due to an instrumental limitation (the imager has only an $\mathrm{OH}$ filter). The observed features, especially the high phase speed, the growth in the number of wave crests with time and the presence of a consistent duct are in agreement with the characteristics expected for bore events (Dewan and Picard, 1998). On the other hand, these characteristics are required but not sufficient to confirm the wave front as a bore event as will be discussed later. Zonal and meridional winds observed with an MF radar at Rothera Station $\left(68^{\circ} \mathrm{S}, 68^{\circ} \mathrm{W}\right)$, and temperature profiles obtained by the SABER instrument on the TIMED satellite were used to characterize the propagation environment. The results show that the wave front reported here was supported by a ducting structure, which is a primary requirement for mesospheric front events (Isler et al., 1997; Dewan and Picard, 1998; Snively et al., 2007; Laughman et al., 2009; Simkhada et al., 2009; Laughman et al., 2011). Our analysis of the wave characteristics and ducting conditions are discussed in detail below.

\section{Observations}

\subsection{Airglow measurements}

A mesospheric gravity waves campaign was carried out at Ferraz Station $\left(62.1^{\circ} \mathrm{S}, 58.4^{\circ} \mathrm{W}\right)$, located on the King George Island, Antarctica, from May to October 2007, using an all-sky CCD imager. The imaging system uses a 2-inch wide band near infrared (NIR) optical filter (715$930 \mathrm{~nm})$, with a notch at $865.5 \mathrm{~nm}$ to suppress the $\mathrm{O}_{2}(0-$ 1) emission to measure $\mathrm{OH}$ airglow emissions near the mesopause $(\sim 87 \mathrm{~km})$. An exposure time of $20 \mathrm{~s}$ was used for each image, yielding a sampling interval of $\sim 38 \mathrm{~s}$ since the imager does not have a filter wheel. The original images $(1024 \times 1024$ pixels $)$ were not binned, but cropped to $512 \times 512$ pixels due to limitations of the optical system (Bageston et al., 2009, 2011), which produces a useful image inside of $312 \times 312$ pixels on the CCD. The quality of the airglow data and its usage were limited by weather conditions to clear sky and new moon periods.

Our data analysis used here was a slightly modified version of the method described in the literature (Garcia and Taylor, 1997; Medeiros et al., 2003). Initially, a sequence of images was selected in order to analyze the wave event that was previously identified in an animation that contains all the images collected in one night. The star field was subtracted from each image that was selected for analysis, and flat field corrections were applied to the image series. Each image in the data set was spatially filtered with a second-order high-pass Butterworth filter, with cutoff frequencies at 8 and $14 \mathrm{~km}$ for projections onto $512 \times 512 \mathrm{~km}$ (resolution of $1 \mathrm{~km} / \mathrm{pixel}$ ) and $768 \times 768 \mathrm{~km}$ (resolution of $1.5 \mathrm{~km} /$ pixel) images, respectively. This filtering process was the modification introduced in the methodology. Finally, the observed images were processed using a 2-D Fast Fourier Transform (FFT) analysis, and a cross spectrum was applied to the sequence of images in order to obtain the horizontal wavelength, observed phase speed, and observed period. 

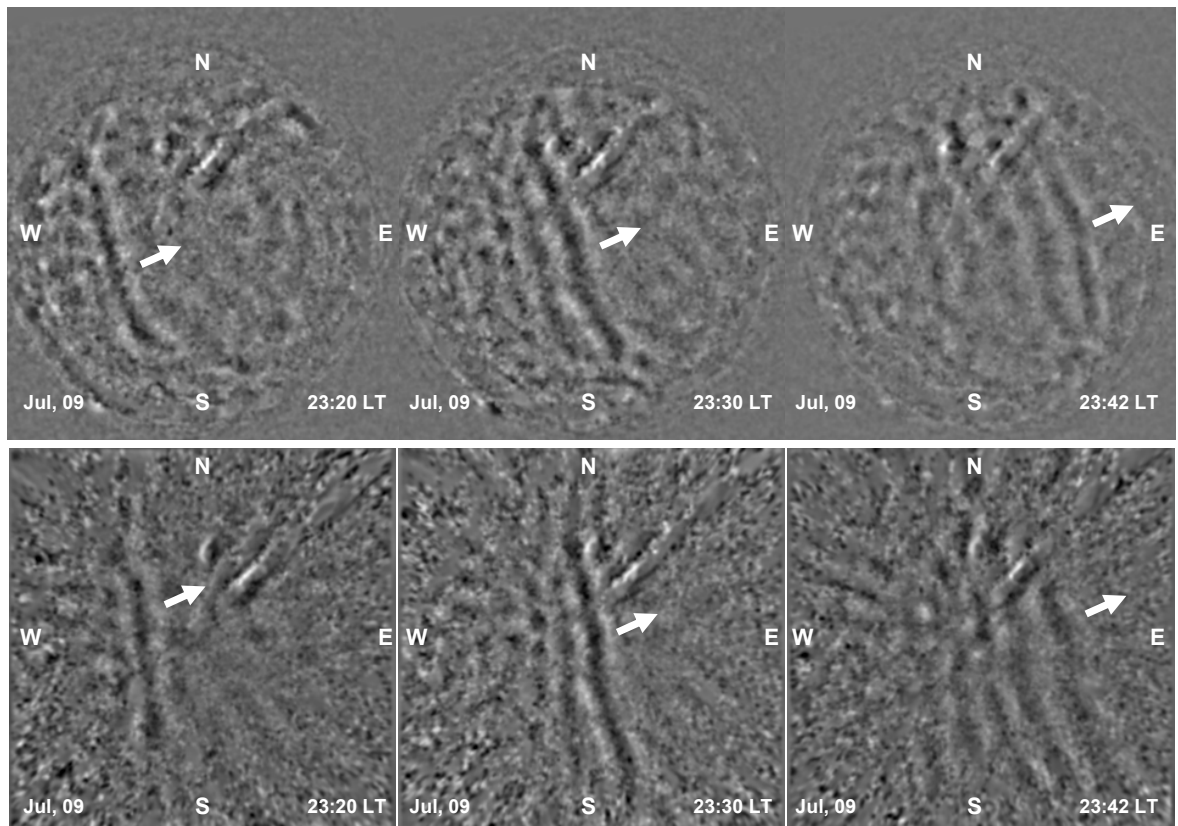

Fig. 1. Processed all-sky OH airglow images at three times spanning about $10 \mathrm{~min}$ on the night of 9-10 July 2007 showing a mesospheric ducted wave propagating from southwest to northeast. In the images shown at the top the star field was subtracted, and then the Time Diference (TD) images process was applied to three different images, skipping the middle image (the used reference time), generating the presented images, and at the bottom the same TD images corrected for the fish-eye lens format are shown.

\subsection{Mesospheric front event}

The mesospheric front was observed from $\sim 23: 00$ to 00:00 LT on the night of 9-10 July 2007 at Ferraz Station at the tip of the Antarctic Peninsula as it progressed from southwest to northeast. Figure 1 presents two rows of images with the same sequence of three processed images (top and bottom) for the event observed in the $\mathrm{OH}$ emission. The first row (top) show the all-sky images after removing the star field and applying the Time Diference (TD) image, i.e. the diference of one image from the previous, separated by about $1.3 \mathrm{~min}$. The second row (bottom) shows the same images but corrected for the all-sky lens format, i.e. the flat fielded images projected onto a regular 312 by 312 spatial grid (sampled at $1 \mathrm{~km}$ ) assuming the $\mathrm{OH}$ peak altitude of $87 \mathrm{~km}$. The arrows ahead of the main front indicate the wave propagation direction.

The mesospheric front reported here is ilustated in Fig. 1. The image at 23:20LT (LT=UT-3) shows the first clear view of the frontal event with a second crest behind the main front. While the wave packet evolves, it is seen the growth in the number of wave crests behind the main front, in an analogous way to the bore events, growing from 1 (at 23:20) to 4 crests $(\sim 23: 40)$ when the wave packet started to show signal of dissipation due to the energy dissipated in the wave train generation itself. It was seen no more than 5 crests (considering the main front) in the wave packet during the propagation time inside the field-of-view of the all-sky imager. Consid- ering the propagation time of $1 \mathrm{~h}$ for the front crossing the field-of-view one can infer a growth rate of 4 waves/h for this event. This result is in agreement with previous observations (Fechine et al., 2005; Nielsen et al., 2006) showing that the number of crests formed behind the fronts could vary from 2 to 12 , and more frequently between 2 and 6 crests (Fechine et al., 2005).

Due to the limitation of the imager, which observed the wave events with only one filter ( $\mathrm{OH}$ emission), we were not able to observe the complementarity effect described by Taylor et al. (1995), i.e. an anti-phase relation in the brightness associated with the wave response seen in different airglow layers. Besides this limitation, the imager system is an adapted airglow system with a camera that is not backilluminated and the system observes the sky in a very small area ( $\sim 312 \times 312$ pixels) without the binning process (that is used to improve the signal-to-noise ratio). All these limitations make that the final images present a low quality, and as consequence in the event presented here we could not identify some kind of step function in the images and neither in the cross-section profiles through the wave packet (including the main front).

From FFT analysis applied to a set of six images from $23: 32$ to $23: 38$ (LT), the following wave parameters were obtained: (a) a horizontal wavelength of $33 \mathrm{~km}$, (b) an observed period of $6 \mathrm{~min}$, and (c) an observed phase speed of $92 \mathrm{~m} \mathrm{~s}^{-1}$. These parameters are very similar to those reported for the wave event observed at Halley Station (Nielsen et al., 
2006), especially the horizontal wavelength and period, with $31 \mathrm{~km}$ and $6.8 \mathrm{~min}$, respectively, seen in the $\mathrm{OH}$ layer. Considering the above characteristics of the mesospheric front and the limitations of imager system we can not qualify the wave event reported here as a mesospheric bore, even considering the consistency of the required duct for this case, as will be showed and discussed later in the Sect. 3. Below we will show the mesospheric environment (winds and temperature) during the observation time of the mesospheric front reported in this study.

\subsection{Mesospheric winds}

Winds in the mesosphere and lower thermosphere (MLT, $\sim 80-100 \mathrm{~km}$ ) are known to have large influences on gravity wave and mesospheric fronts propagation in MLT, depending on their propagation direction. Wind measurements were not available at Ferraz during the wave event observation. However, mesospheric wind measurements were available with an MF radar at Rothera Station $\sim 765 \mathrm{~km}$ to the south, as employed in the study by Bageston et al. (2011). The Rothera MF radar measures horizontal winds in the MLT through analysis of D-region partial reflection echoes (Jarvis et al., 1999; Hibbins et al., 2007). The radar operates at a frequency of $1.98 \mathrm{MHz}$ with a transmitter power of $25 \mathrm{~kW}$ and full-width half-maximum pulse width of $25 \mu \mathrm{s}$, which corresponds to a height resolution of $\sim 4 \mathrm{~km}$, with returns oversampled at $2 \mathrm{~km}$ intervals (Hibbins et al., 2007). Data used here are restricted to altitudes below $94 \mathrm{~km}$ as several authors have observed that MF radars tend to underestimate wind speeds compared to those observed by meteor radars at higher altitudes (e.g. Manson et al., 2004 and Portnyagin et al., 2004).

Rothera winds surely do not describe the small-scale winds over Ferraz, but very similar tidal structures are seen at sites with similar spacing extending across the Drake Passage (Fritts et al., 2011), and large-scale inertia-gravity waves (IGWs) having vertical wavelengths of $\sim 10 \mathrm{~km}$ or more imply similar structures somewhat shifted in phase at distances up to $\sim 1000 \mathrm{~km}$ or more away. Assuming (as shown below) that tidal and IGW structures dominate the wave ducting environment, Rothera winds will allow us to estimate roughly the intrinsic parameters for the wave front event.

Winds along the wave propagation direction obtained with the Rothera MF radar during the wave event are shown in Fig. 2a. This profile was obtained by the hourly wind observed during the time duration of the event, interpolating to $1-\mathrm{km}$ vertical resolution, and then averaging over $3 \mathrm{~km}$ in the vertical in order to remove vertical structure expected to not be coherent over large distances. The dominant structure seen has a vertical wavelength of $\sim 10 \mathrm{~km}$ and a near-inertial period (see data analysis and discussion below), suggesting a dominant large-scale IGW with perhaps tidal contributions. Further analysis and discussion of these data and their implications for the wave environment will be provided below.

\subsection{Mesospheric temperatures}

During Southern Hemisphere winter, SABER views towards high southern latitudes, so measurements are occasionally available very near Ferraz (Russell et al., 1999; Mertens et al., 2004). For this study, the nearest SABER profile was obtained $\sim 1300 \mathrm{~km}$ north of Ferraz, and about $140 \mathrm{~min}$ before the wave front was seen. This distance is larger than desired, but it is the only profile sufficiently close to Ferraz to be useful, it is likely much more representative of the thermal structure over Ferraz than a climatology would be, and the extent of the wave event noted above is of the order of the imager field-of-view, suggesting that the ducting environment has a large horizontal extent. This temperature profile is shown in Fig. 2b. The implications of this temperature profile for ducting and wave propagation will be explored further below.

An imaging spectrometer was collocated with the all-sky imager at Ferraz during the wave front event observation. However, the field-of-view over which the spectrometer observes the sky as an integrated counting of the $\mathrm{OH}$ (6-2) emission is $\sim 70 \mathrm{~km}$ in diameter about the zenith (Bageston et al., 2007), that is more than twice the horizontal wavelength of the wave identified in the all-sky images presented in Fig. 1. This means that the field-of-view on which we calculate the temperature is larger than the horizontal scale of the wave event. The spectrometer data showed evidence of a smallscale wave with period about 10-min, larger than the period infered from the all-sky images. Hence, the temperature time series showed no evidence of the 6-min wave period inferred from the all-sky imager data, so the spectrometer data were not employed in this analysis.

\section{Analysis and discussion}

To investigate the large-scale MLT propagation environment during the wave event observation, we use the Rothera MF radar winds and the SABER temperature profile to compute the vertical profile of $m^{2}$, where $m=2 \pi / \lambda_{z}$ is the vertical wavenumber and $\lambda_{z}$ is the local vertical wavelength for positive $m^{2}$. The resulting $m^{2}$ profile suggests a duct for gravity waves in a region where $m^{2}>0$ that is between two regions having $m^{2}<0$ (in which the relevant motions are evanescent in the vertical) having sufficient depth to cause effective trapping of the disturbance at the $m^{2}$ maximum. The approximate dispersion relation, including wind curvature effects, but neglecting shear effects, is given by

$m^{2}=\left[\frac{N^{2}}{\left(u_{0}-c\right)^{2}}-\frac{u_{0}^{\prime \prime}}{u_{0}-c}-k_{\mathrm{h}}^{2}\right]$,

where $N$ is the buoyancy frequency, $u_{0}$ is the horizontal wind in the direction of the wave propagation, $u_{0}^{\prime \prime}$ is the second derivative of the wind with altitude, $c$ is the observed phase speed, $k_{\mathrm{h}}=2 \pi / \lambda_{\mathrm{h}}$ is the horizontal wavenumber, and $\lambda_{\mathrm{h}}$ is the horizontal wavelength. This dispersion relation is valid 

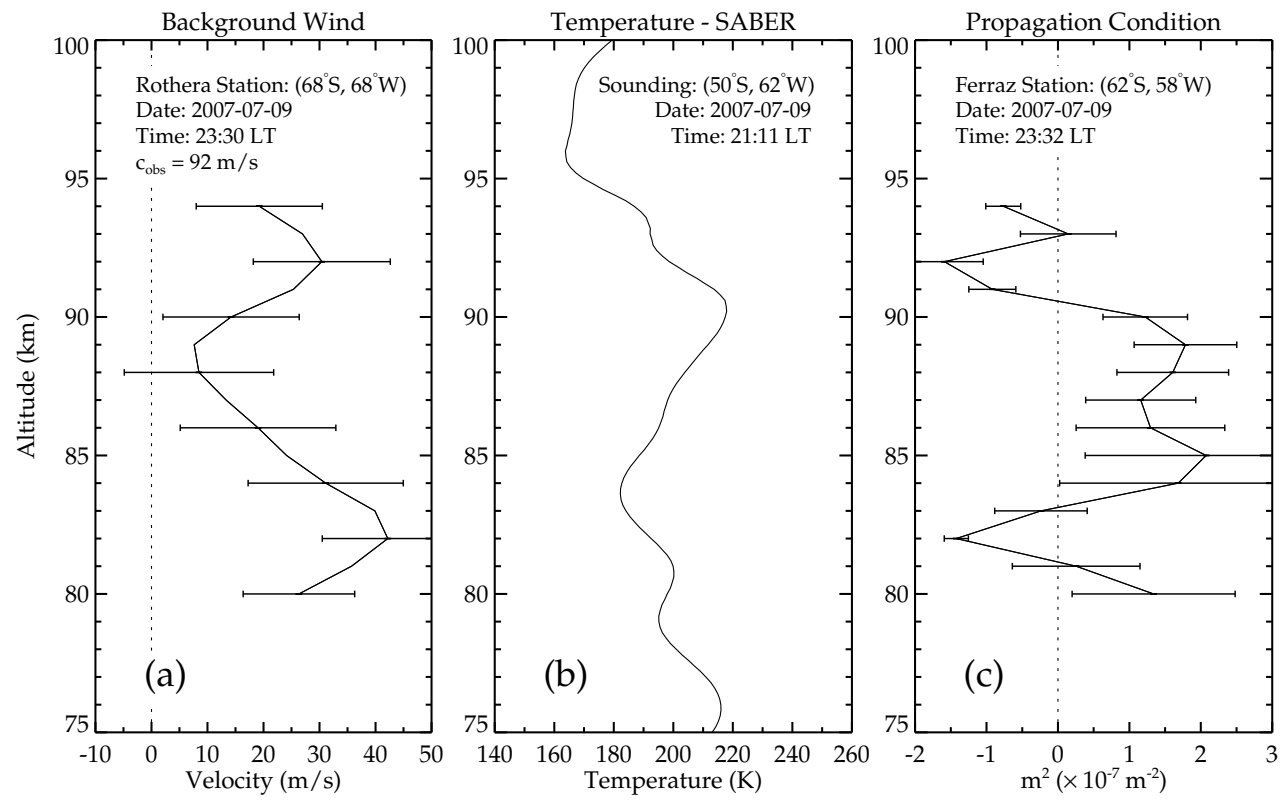

Fig. 2. (a) Wind profile in the wave propagation direction obtained by a MF radar at Rothera Station during the wave event observation. (b) Temperature profile obtained by SABER on 9 July 2007 to the north of Ferraz and 140 min prior to the wave observation. (c) Vertical wavenumber squared $\left(\mathrm{m}^{2}\right)$ showing a duct region between $\sim 84$ and $\sim 90 \mathrm{~km}$.

for gravity waves propagating in an environment where the effects of horizontal winds and temperature gradients cannot be neglected (Chimonas and Hines, 1986; Isler et al., 1997; Fritts and Yuan, 1989).

The buoyancy frequency, $N$, can be estimated using the relation (2):

$N^{2}=\frac{g}{T}\left(\nabla T_{z}+\frac{g}{C_{p}}\right)$,

where $g$ is the acceleration due to gravity, $T$ is temperature, $C_{p}=1005 \mathrm{~J} \mathrm{~kg}^{-1} \mathrm{~K}^{-1}$ is the specific heat at constant pressure, $\nabla T_{z}$ is the vertical temperature gradient, and $\frac{g}{C_{p}} \sim 9.5 \mathrm{~K} \mathrm{~kg}^{-1}$ at MLT altitudes.

The vertical profile of $m^{2}$ obtained from Eq. (1) for the horizontal wind and temperature profiles shown in Fig. 2a and b is shown in Fig. 2c. Sensitivity to the details of the SABER temperature profile was evaluated by shifting it vertically by $\pm 3 \mathrm{~km}$, that showed a consistency of the duct structure which was also shifted vertically, above and below of the nominal $\mathrm{OH}$ peak, but not changing significantly its shape. This suggested that the ducting environment is much more dependent on the structure of the wind profile than on the temperature profile, with the curvature term being particularly important. It is clear from these profiles that the wave front event was supported by a large-scale duct between $\sim 83$ and $90 \mathrm{~km}$, within which $\left(m^{2}>0\right)$, with evanescent regions $\left(m^{2}<0\right)$ above and below. These profiles also suggest that the duct coincides closely with the altitude of the $\mathrm{OH}$ airglow layer (Marsh et al., 2006), though we also note that the true ducting environment over Ferraz may have exhibited a different phase structure of the low-frequency motions than observed over Rothera, potentially resulting in a ducting structure centered at somewhat higher or lower altitudes than shown in Fig. 2c.

The observed phase speed of the wave packet estimated from the 2-D FFT cross spectrum of the airglow images discussed above was $92 \mathrm{~m} \mathrm{~s}^{-1}$. This is $\sim 50 \mathrm{~m} \mathrm{~s}^{-1}$ faster than the wind along the wave front propagation direction at any altitude, and $\sim 70 \mathrm{~m} \mathrm{~s}^{-1}$ faster than the mean wind at the center of the primary ducting region (see Fig. 2a and c), where the maximum values of $m^{2}$ are implied by the maximum positive temperature gradients (see Fig. 2b). Indeed, temperature inversions, or thermal ducts, have often been associated with mesospheric fronts (Dewan and Picard, 1998, 2001; Smith et al., 2003; She et al., 2004; Smith et al., 2005; Narayanan et al., 2009; Laughman et al., 2009, 2011; Bageston et al., 2011). The intrinsic phase speed along the direction of propagation implied by the estimated $\mathrm{m}^{2}$ profile is from $\sim 50$ to $70 \mathrm{~m} \mathrm{~s}^{-1}$, depending on whether we take the relevant background wind to be the maximum in the direction of propagation or that centered in the ducting region (with $m^{2}>0$ ). Assuming the latter is most relevant, we infer a corresponding intrinsic period of $\sim 8 \mathrm{~min}$.

In a related study, Fechine et al. (2009) performed a comparative analysis of the terms in the dispersion relation for a bore observation. They inferred that it was likely supported by a Doppler duct, with apparent influences by the semidiurnal tide. Bageston et al. (2011) analyzed a mesospheric wall event over Ferraz and concluded that it was 

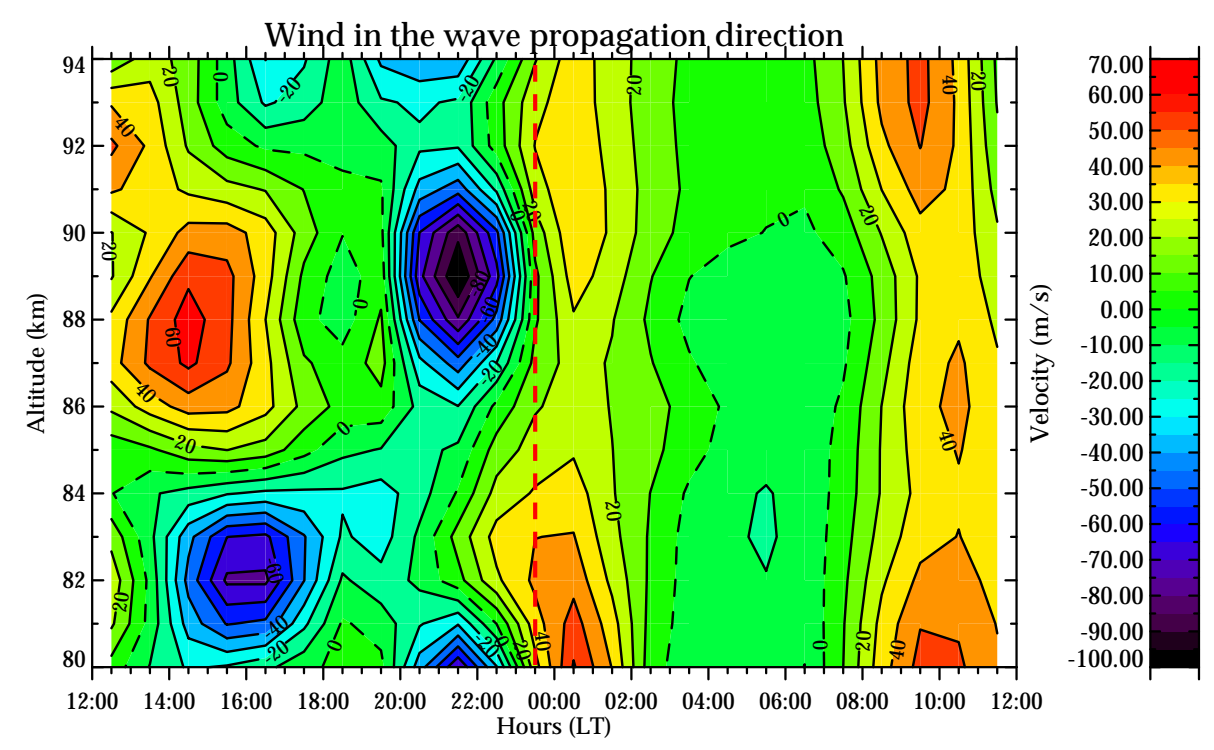

Fig. 3. Contour plot of the Rothera winds in the wave propagation direction, $50^{\circ}$ clockwise from north, from 12:00 LT on 9 July to $12: 00 \mathrm{LT}$ on 10 July. The vertical dashed red line indicates the time when the wave front was at zenith.

supported by a thermal duct, with the winds having little effect on the duct configuration. More recently, Stockwell et al. (2011) estimated the bore duct depth and its variability for the bore event reported for Antarctic latitudes (Nielsen et al., 2006; Stockwell et al., 2006). In the analysis performed by Stockwell et al. (2011) no evidence of Doppler duct was observed, and no analysis of thermal duct was conducted since they did not have any observed temperature data.

We now examine the influences of the wind field we have assumed to apply in the present case in greater detail. Figure 3 shows a contour plot for the hourly-averaged wind component along the wave front propagation direction observed over 24 hfrom 12:00 LT on 9 July to 12:00 LT on 10 July 2007. The vertical dashed red line at 23:30 LT on 9 July denotes the time when the mesospheric front was near zenith in the all-sky images. This figure indicates both shorterperiod motions (periods of $\sim 4$ to $6 \mathrm{~h}$ ) and longer-period motions (likely IGW or semidiurnal tide winds), with the former achieving the largest amplitudes prior to observation of the wave front event. Of the observed motions, we expect that only the lower-frequency components would have had the potential to also occur over Ferraz without large phase and amplitude variations. This is because large horizontal winds imply relatively large vertical wavelengths and shorter observed periods imply smaller horizontal wavelengths. Assuming that the observed periods are indicative of comparable intrinsic periods, this would result in much less coherence at large horizontal distances. Thus, we focus on the longerperiod motions hereafter.
A Morlet wavelet analysis (Torrence and Compo, 1998) was used to identify the dominant low-frequency oscillations centered on the day and time of the wave front observation. We used a wind time series at $86 \mathrm{~km}$ near the center of the duct extending over $\sim 3$ days, from 00:00 LT on 9 July to 18:00 LT on 11 July, for this purpose.

Figure 4a shows the result of the Morlet wavelet spectral analysis of the wind time series presented in Fig. 4b (black line). The power spectrum describes periods from 4 to $33 \mathrm{~h}$ as functions of time. Solid black lines indicate regions where the confidence level is higher than $90 \%$, while the dashed black lines define the region where the results are confident excluding the border effects. The white vertical dashed line indicates the time when the mesospheric front was seen in the zenith by the all-sky imager. Clearly seen in Fig. 4a is a maximum in spectral density centered at a period of $\sim 10 \mathrm{~h}$, consistent with dominance of the wind field by some combination of IGWs and semidiurnal and terdiurnal tides at this time. Motivated by this result, a band-pass filter was applied to the original wind time series at $86 \mathrm{~km}$ high for periods between 6 and $14 \mathrm{~h}$. The filtered time series is shown as a red line in Fig. 4b, and is seen to be consistent with the periodicities observed in the unfiltered time series in Fig. 4b. These results suggest that if the wind was important in defining the ducting structure, then the low-frequency IGW and tidal contributions would have played key roles. The relative importance of the tidal winds and the thermal structure in defining the ducting environment is discussed further below.

In order to assess the tidal contributions to the $\mathrm{m}^{2}$ profile and potential influences on wave ducting, we employ the least mean square method, which makes use of the well established classical harmonic fitting. Details of this method 

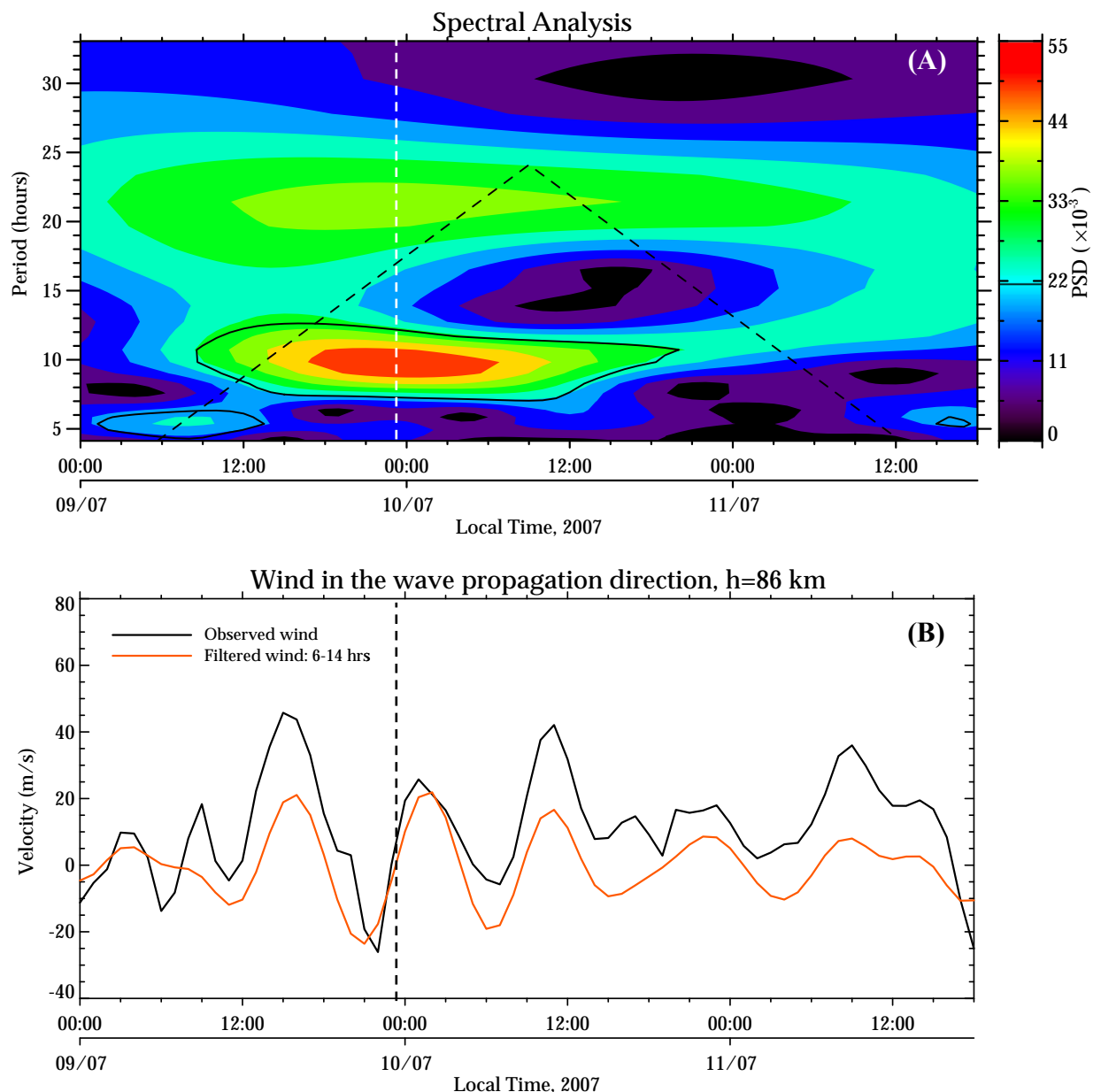

Fig. 4. (a) Wavelet spectral analysis of the observed wind at $86 \mathrm{~km}$ from $9-11$ July showing periods from $\sim 4$ to $12 \mathrm{~h}$. Solid black lines indicate confidence levels greater than $90 \%$; dashed black lines show the region uninfluenced by edge effects. (b) Wind in the wave propagation direction at $86 \mathrm{~km}$ (black line), and a wavelet filtering of the same wind between cutoff periods of 6 and $14 \mathrm{~h}$ (red line). Vertical dashed lines indicate the time when the ducted wave was near zenith.

and the equation employed for fitting the winds (and consequentely to obtain the tidal amplitudes and phases) are found in the work of Andrioli et al. (2009). Following this methodology we are able to reconstruct the wind profiles by means of the amplitude and phase associated to the tidal modes. In our case, it was identified that only the semi-diurnal and terdiurnal modes were present around the observation time of the mesospheric front and these periodicities were used to reconstruct the vertical wind profiles near the time in which the wave was seen in the all-sky images. We did not evaluate the contribution from the low-frequency IGW apart of the tides, since the winds reconstruction using just the tidal oscillations produced a good fit in comparison to the observed wind (see Fig. 5b). The winds reconstruction was performed in two ways, at first the tidal components were included, and later the wind contribution due to the tides was removed in order to observe the relative contribution of the tides in the observed duct. Here, the mean wind field was defined as the wind field smoothed as described above after removal of the tides. The mean wind $\left(V_{0}\right)$ defined here did not includes the low-frequency IGW motions, since its periods were not included in the harmonic fitting.

The resulting $\mathrm{m}^{2}$ profiles, wind profiles averaged from 23:00 to 24:00 LT on 9 July, and curvature terms are shown in Fig. 5a, b, and c, respectively. In the plots, black lines denote the profiles employing the full wind field as observed with the MF radar (which include tides, low-frequency IGWs and other low-frequency motions), dashed black lines in (a) and (c) are related to the calculations using $N^{2}$ constant (as shown in doted red line in (c)) but with the observed wind, blue lines denote results using only the mean wind, and red lines denote results using the tidal winds added to the mean wind. The buoyancy frequency squared and the corresponding term in the dispersion relation, assuming the full wind field and the observed temperature profile, are shown in solid red and black lines, respectively, in Fig. 5d. 

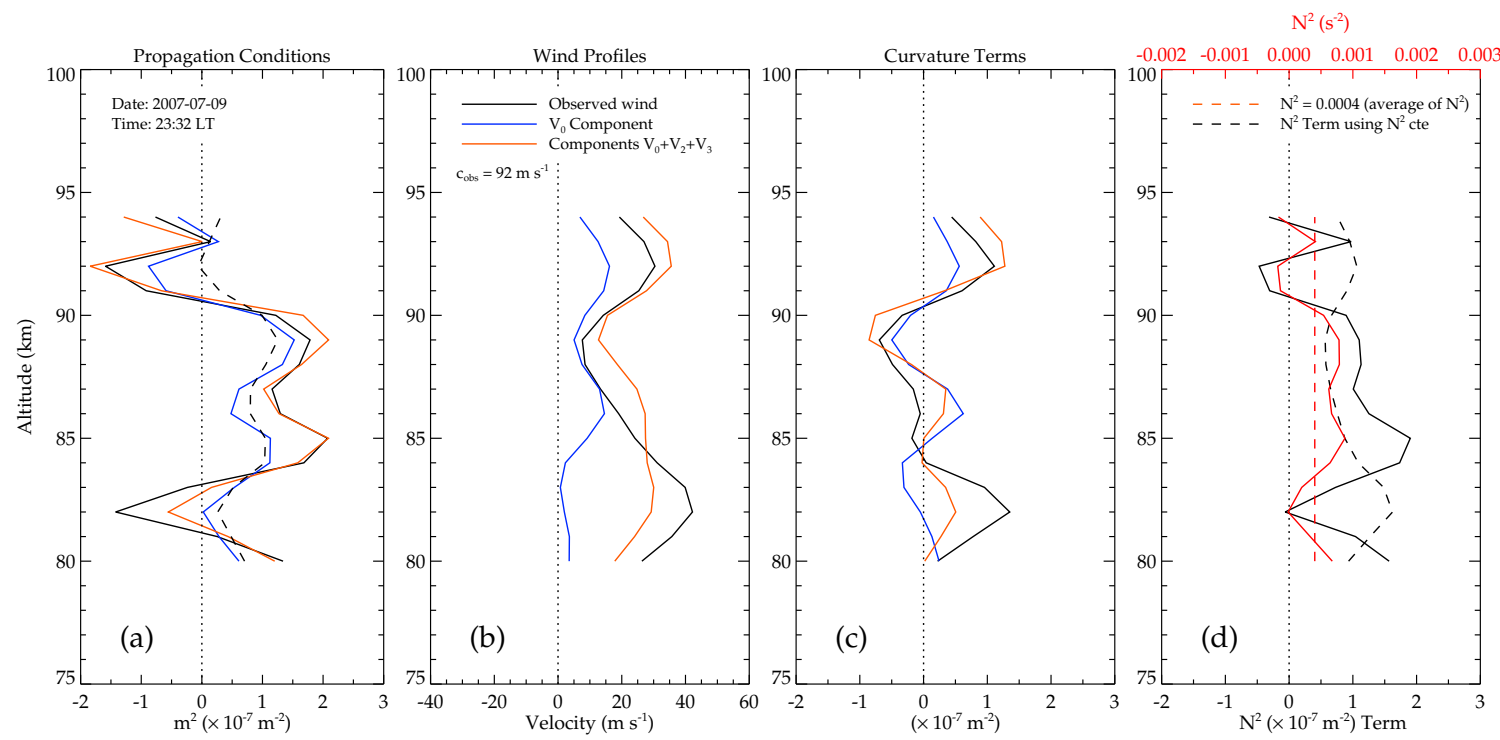

Fig. 5. (a) Profiles of $m^{2}$ for different conditions, namely wind profiles shown in (b): observed wind (black); mean wind (without tides, blue) and tidal winds plus the mean wind (red), and constant buoyancy frequency (dashed black line) as labeled in (d). (c) Curvature terms due to the winds in (b). (d) $N^{2}$ (red, upper axis) varying with the temperature (solid line) and its mean value (constant dashed line), and the buoyancy term contribution to $m^{2}$ (black, lower axis) due to $N^{2}$ varying with the temperature (solid line) and $N^{2}$ constant (dashed line) for comparison with panels (a) and (c).

Comparing the various profiles in Fig. 5a, we see that all exhibit a region of maximum (positive) $m^{2}$ at altitudes $\sim 84$ to $90 \mathrm{~km}$, despite the varying contributions of wind magnitudes, curvature terms and buoyancy frequency squared. This latter implies a significant role of the large and sustained temperature gradient spanning these altitudes in defining the ducting structure. We also see much smaller differences between the solid black and red profiles in panels (a), (b), and (c) than between the solid black and blue profiles. The blue and dashed black profiles of $m^{2}$ suggests that there is no evanescent region adjacent to the duct at lower altitudes, and that this structure may not support ducted or mesospheric front responses at all. It is also observed that the relative importance of the tidal winds and the varying temperature profile (or $N^{2}$ profile) to the $m^{2}$ are equivalente, and besides that it should be noted that when any of these two imposed conditions, tides or varying $N^{2}$, is removed from the $m^{2}$ dispersion relation the actual duct condition disapears, as can be seen in the blue and dashed black profiles in Fig. 5a.

These combined results indicate that the tides and lowfrequency motions make a significant contribution to ducting structure enabling mesospheric fronts or other ducted waves propagate for long distances at mesospheric heights, particularly in combination with enhanced stability (and temperature gradient) at the ducting level. Even if the wind field over Ferraz was somewhat different in phase (and altitude) than measured over Rothera, we expect the low-frequency IGW and tidal motions to impose ducting structure similar to that shown in Fig. 5, given the apparent importance of the wind and curvature terms in the dispersion relation, provided that some portion of the implied increase in $m^{2}$ due to the wind field coincides with the stability enhancement between $\sim 84$ and $90 \mathrm{~km}$. We should notice that atmospheric tides can affect the wind structure as well as the temperature field and airglow brightness (see evidences of semi-diurnal tide presented by Smith et al., 2006), but in our study it does not appear that the temperature enhancement (inversion layer) seen in Fig. $2 b$ have been induced by the same tidal components identified in the horizontal wind (Figs. 3 and 4). This should be true for some basic reasons: first, the average temperature profile (not shown here) within $-7 /+7 \mathrm{~h}$ centered in the wave event time did not show similar temperature structure (presence of inversion layer) as the one seen in Fig. 2b; second, we did not see any evidence of tidal effects in the time series of the $\mathrm{OH}$ rotational temperature and airglow intensity as measured by the airglow spectrometer, and third, the temperature structures at high latitudes are less affected by tides and likely at distinct harmonic components, when compared to the horizontal winds according with the classical theory (Chapman and Lindzen, 1970).

In order to compare the relative importance of the Doppler shift and the wind curvature in the dispersion relation, we can just analyze the second term on the right hand side of the Eq. (1), that is shown in Fig. 5c for different wind profiles. For example, the Doppler shift $\left(u_{0}-c\right)$ for a wind velocity of about $40 \mathrm{~m} \mathrm{~s}^{-1}$ (observed wind at about $82 \mathrm{~km}$ ) gives a value of $\sim-52 \mathrm{~m} \mathrm{~s}^{-1}$, while the curvature term $u_{0}^{\prime \prime} /\left(u_{0}-c\right)$ is $\sim 1.5 \times 10^{-7}$ and so we could infer that $u_{0}^{\prime \prime} \sim 10^{-6}$, showing 
that the Doppler shift is much higher than the wind curvature. The observed results showed that the contribution of the curvature term for the $m^{2}$ was similar to the term of the buoyancy frequency squared.

Concurrent observations of airglow temperature and winds together with modeling (Snively et al., 2007; Simkhada et al., 2009) have demonstrated the importance of winds in producing Doppler duct at the mesospheric heights in order to permit that mesospheric front events or any other ducted wave be able to propagate horizontaly for long distances in these altitudes. Besides these previous results, Hecht et al. (2009) suggested that planetary waves (especially the quasi two-day waves) could have an important role in the temperature inversions, causing them to persist in the MLT region for a period of the order of two days thereby maintaining the presence of consistent ducts in combination with the winds. Together, our results imply a duct that depends on both the wind and temperature fields, that are consistent with expectations of theoretical studies of these dynamics (Fritts and Yuan, 1989; Laughman et al., 2009) and also with expectations from observations of mesospheric fronts (Smith et al., 2006).

\section{Conclusions}

We described a wave front event, followed by a set of ducted waves, observed by an all-sky airglow imager over Ferraz Station on the night of 9-10 July 2007. The ducting environment was assumed to be of large spatial extent, given the extent of the front itself across the full field-of-view of the imager. We thus employed winds measured at Rothera Station to the south of Ferraz and a temperature profile measured by SABER on TIMED to the north, and somewhat earlier than the wave observation, to evaluate the environmental factors likely to have enabled the ducted waves propagation. Our analysis revealed that tidal motions and low-frequency IGW were likely responsible for the wind structure contributing to the ducting environment, but that a maximum in $N^{2}$ due to a large positive temperature gradient $(\sim 40 \mathrm{~K}$ extending over $\sim 6 \mathrm{~km}$ ) also contributed to the duct supporting the mesospheric front propagation. The observed wave front event could not be qualified as a bore event due to the lack of additional observational evidence. Specifically, a clear step function in the main front was not identified, and the observation of the event in other airglow layers was not possible since the imager has only an $\mathrm{OH}$ filter. In particular, the winds were found to be essential in defining the ducting environment in this case, in contrast to other front events where the temperature structure alone appeared to be sufficient to enable ducting. Earlier published work, has shown that vertical structures in winds can generate Doppler ducts which would be able to support mesospheric fronts. However, for the event considered here, we have shown that the winds alone could not generate consistent ducts. In the present study it was necessary to include the contribution of the thermal structure together with the winds contribution in order to have a well defined duct, i.e. the thermal-Doppler ducting analyzed here. Future observations at Ferraz Station will benefit from local wind measurements by a new meteor radar recently installed at that site.

Acknowledgements. The present research was supported by FAPESP under the grant $n^{\circ} 2010 / 06608-2$, and partially by $\mathrm{CNPq}$ (grant no. 151593/2009-4). Also, this work combines results of the INCT-APA (CNPq process no. 574018/2008-5, FAPERJ process no. E-26/170.023/2008) in the project "Study of the Mesosphere, Stratosphere and Troposphere over Antarctica and its connections with the Southern America (ATMANTAR)", under process no. 52.0182/2006-5, Proantar/MCT/CNPq. The authors thank the Secretariat of the Interministerial Commission for the Resources of the Sea (SECIRM). Support for the Rothera MF radar was jointly supported by National Science Foundation grant OPP-0839084 and by the UK Natural Environment Research Council. We also thank the TIMED/SABER team, especially M. G. Mlynczak and J. M. Russell, for providing SABER data and J. Fechine for processing these SABER data. Wavelet software used in the present work was provided by C. Torrence and G. Compo and is available at http://paos.colorado.edu/research/wavelets/. C. M. Wrasse thanks CNPq for the support under the grant no. 304277/2008-8.

Edited by: W. Ward

\section{References}

Andrioli, V. F., Clemesha, B. R., Batista, P. P. and Schuch, N. J.: Atmospheric tides and mean winds in the meteor region over Santa Maria $\left(29.78^{\circ} \mathrm{S} ; 53.88^{\circ} \mathrm{W}\right)$, J. Atmos. Sol-Terr. Phys., 71, 1864 1876, doi:10.1016/j.jastp.2009.07.005, 2009.

Bageston, J. V., Gobbi, D., Tahakashi, H., and Wrasse, C. M.: Development of Airglow $\mathrm{OH}$ Temperature Imager for Mesospheric Study, http://www.scielo.br/, Braz. J. Geophys., 25, 27-34, 2007.

Bageston, J. V., Wrasse, C. M., Gobbi, D., Takahashi, H., and Souza, P. B.: Observation of mesospheric gravity waves at Comandante Ferraz Antarctica Station ( $\left.62^{\circ} \mathrm{S}\right)$, Ann. Geophys., 27, 2593-2598, doi:10.5194/angeo-27-2593-2009, 2009.

Bageston, J. V., Wrasse, C. M., Hibbins, R. E., Batista, P. P., Gobbi, D., Takahashi, H., Andrioli, V. F., Fechine, J., and Denardini, C. M.: Case study of a mesospheric wall event over Ferraz station, Antarctica (62 ${ }^{\circ}$ S), Ann. Geophys., 29, 209-219, doi:10.5194/angeo-29-209-2011, 2011.

Brown, L. B., Gerrard, A. J., Meriwether, J. W., and Makela, J. J. All-sky imaging observations of mesospheric fronts in OI $557.7 \mathrm{~nm}$ and broadband $\mathrm{OH}$ airglow emissions: Analysis of frontal structure, atmospheric background conditions, and potential sourcing mechanisms,J. Geophys. Res., 109, D19104, doi:10.1029/2003JD004223, 2004.

Chapman, S. and Lindzen, R. S.: Atmospheric tides: thermal and gravitational. D. Reidel Publishing Company and DordrechtHolland, 200 pp., 1970.

Chimonas, G. and Hines, C. O.: Doppler Ducting of Atmospheric Gravity-Waves, J. Geophys. Res., 91, 1219-1230, 1986.

Dewan, E. and Picard, R.: Mesospheric bores, J. Geophys. Res., 103, 6295-6305, 1998. 
Dewan, E., and Picard, R.: On the origin of mesospheric bores, J. Geophys. Res., 106, 2921-2927, 2001.

Fechine, J., Medeiros, A. F., Buriti, R. A., Takahashi, H., and Gobbi, D.: Mesospheric bore events in the equatorial middle atmosphere, J. Atmos. Sol-Terr. Phys., 67, 1774-1778, doi:10.1016/j.jastp.2005.04.006, 2005.

Fechine, J., Wrasse, C. M., Takahashi, H., Medeiros, A. F., Batista, P. P., Clemesha, B. R., Lima, L. M., Fritts, D., Laughman, B., Taylor, M. J., Pautet, P. D., Mlynczak, M. G., and Russell, J. M.: First observation of an undular mesospheric bore in a Doppler duct, Ann. Geophys., 27, 1399-1406, doi:10.5194/angeo-271399-2009, 2009.

Fritts, D. C. and Yuan, L.: An Analysis of Gravity Wave Ducting in the Atmosphere: Eckart's Resonances in Thermal and Doppler Ducts, J. Geophys. Res., 94, 18455-18466, doi:10.1029/JD094iD15p18455, 1989.

Fritts, D. C, Janches, D., Iimura, K., Hocking, W. K., Bageston, J. V., and Leme, N. M. P.: Drake Antarctic Agile Meteor Radar (DrAAMER) First Results: Configuration and Comparison of Mean and Tidal Wind and Gravity Wave Momentum Flux Measurements with SAAMER, J. Geophys. Res., accepted, 2011.

Garcia, F.J. and Taylor, M.J.: Two-dimensional spectra-analysis of mesospheric airglow data, Appl. Opt., 36, 7374-7385, 1997.

Hecht,J. H., Alexander, M. J. , Walterscheid, R. L., Gelinas,L. J., Vincent, R. A., MacKinnon,A. D., Woithe, J. M., May, P. T., Skinner, W. R., Mlynczak, M. G., and Russell, III, J. M.: Imaging of atmospheric gravity waves in the stratosphere and upper mesosphere using satellite and ground-based observations over Australia during the TWPICE campaign, J. Geophys. Res., 114, D18123, doi:10.1029/2008JD011259, 2009.

Hibbins, R. E., Espy, P. J., Jarvis, M. J., Riggin, D. M., and Fritts, D. C.: A climatology of tides and gravity wave variance in the MLT above Rothera, Antarctica obtained by MF radar, J. Atmos. SolTerr. Phys., 69, 578-588, doi:10.1016/j.jastp.2006.10.009, 2007.

Isler, J. R., Taylor, M. J., and Fritts, D. C.: Observational Evidence of Wave Ducting and Evanescence in the Mesosphere, J. Geophys. Res., 102, 26301-26313, 1997.

Jarvis, M. J., Jones, G. O. L., and Jenkins, B.: New initiatives in observing the Antarctic mesosphere, Adv. Space Res., 24, 611619, 1999.

Laughman, B., Fritts, D. C., and Werne, J.: Numerical simulation of bore generation and morphology in thermal and Doppler ducts, Ann. Geophys., 27, 511-523, doi:10.5194/angeo-27-511-2009, 2009.

Laughman, B., Fritts, D. C., and Werne, J.: Comparisons of predicted bore evolutions by the Benjamin-Davis-Ono and NavierStokes equations for idealized mesopause thermal ducts, J. Geophys. Res., 116, D02120, doi:1029/2010JD014409, 2011.

Manson, A. H., Meek, C. E., Hall, C. M., Nozawa, S., Mitchell, N. J., Pancheva, D., Singer, W., and Hoffmann, P.: Mesopause dynamics from the scandinavian triangle of radars within the PSMOS-DATAR Project, Ann. Geophys., 22, 367-386, doi:10.5194/angeo-22-367-2004, 2004.

Marsh, D. R., Smith, A. K., Mlynczak, M. G., and Russell III, J. M.: SABER observations of the $\mathrm{OH}$ Meinel airglow variability near the mesopause, J. Geophys. Res., 111, A10S05, doi:10.1029/2005JA011451, 2006.

Medeiros, A. F., Taylor, M. J., Takahashi, H., Batista, P. P., and Gobbi, D.: An Investigation of gravity wave activity in the low- latitude upper mesosphere: propagation direction and wind filtering, J. Geophys. Res., 108, 4411, doi:10.1029/2002JD002593, 2003.

Medeiros, A., Fechine, J., Buriti, R. A., H. Takahashi, Wrasse, C. M., and Gobbi, D.: Response of $\mathrm{OH}, \mathrm{O}_{2}$ and OI5577 airglow emissions to the mesospheric bore in the equatorial region of Brazil, Adv. Space Res., 35, 1971-1975, doi:10.1016/j.asr.2005.03.075, 2005.

Mertens, C. J., Schmidlin, F. J., Goldberg, R. A., Remsberg, E. E., Pesnell, W. D., Russell III, J. M., Mlynczak, M. G., LupezPuertas, M., Wintersteiner, P. P., Picard, R. H., Winick, J. R., and Gordley, L. L.: SABER observations of mesospheric temperatures and comparisons with falling sphere measurements taken during the 2002 Summer MaCWAVE campaign, Geophys. Res. Lett., 31, L03105, doi:10.1029/2003GL018605, 2004.

Narayanan, V. L., Gurubaran, S., and Emperumal, K.: A case study of a mesospheric bore event observed with an all-sky airglow imager at Tirunelveli $\left(8.7^{\circ} \mathrm{N}\right)$, J. Geophys. Res., 114, D08114, doi:10.1029/2008JD010602, 2009.

Nielsen, K., Taylor, M. J., Stockwell, R., and Jarvis, M.: An unusual mesospheric bore event observed at hight latitudes over Antarctica, Geophys. Res. Lett., 33, L07803, doi:10.1029/2005GL025649, 2006.

Portnyagin, Y. I., Solovjova, T. V., Makarov, N. A., Merzlyakov, E. G., Manson, A. H., Meek, C. E., Hocking, W., Mitchell, N., Pancheva, D., Hoffmann, P., Singer, W., Murayama, Y., Igarashi, K., Forbes, J. M., Palo, S., Hall, C., and Nozawa, S.: Monthly mean climatology of the prevailing winds and tides in the Arctic mesosphere/lower thermosphere, Ann. Geophys., 22, 33953410, doi:10.5194/angeo-22-3395-2004, 2004.

Russell III, J. M., Mlynczak, M. G., Gordley, L. L., Tansock, J., and Esplin, R.: An overview of the SABER experiment and preliminary calibration results, Proceedings of the SPIE, 44th Annual Meeting, Denver, Colorado, 18-23 July, 3756, 277-288, 1999.

She, C. Y., Li, T., Williams, B. P., Yuan, T., and Picard, R. H.: Concurrent $\mathrm{OH}$ imager and sodium temperature/wind lidar observation of a mesopause region undular bore event over Fort Collins/Platteville, Colorado, J. Geophys. Res., 109, 2210722115, doi:10.1029/2004JD004742, 2004.

Simkhada, D. B., Snively, J. B., Taylor, M. J., and Franke, S. J.: Analysis and modeling of ducted and evanescent gravity waves observed in the Hawaiian airglow, Ann. Geophys., 27, 32133224, doi:10.5194/angeo-27-3213-2009, 2009.

Smith, S. M., Taylor, M. J., Swenson, G. R., She, C., Hocking, W., Baumgardner, J., and Mendillo, M. A.: Multidiagnostic investigation of the mesospheric bore phenomenon, J. Geophys. Res., 108, 13-18, doi:10.1029/2002JA009500, 2003.

Smith, S. M., Friedman, J., Raizada, S., Tepley, C.; Baumgardner, J., and Mendillo, M.: Evidence of mesospheric bore formation from a breaking gravity wave event: Simultaneuous imaging and lidar measurements, J. Atmos. Sol-Terr. Phys., 67, 345-356, 2005.

Smith, S. M., Scheer, J., Reisin, E. R., Baumgardner, J., and Mendillo, M.: Characterization of exceptionally strong mesospheric wave events using all-sky and zenith airglow observations, J. Geophys. Res., 111, A09309, doi:10.1029/2005JA011197, 2006.

Snively, J. B., Pasko, V. P., Taylor, M. J., and Hocking, W. K.: Doppler ducting of short-period gravity waves by mid- 
latitude tidal wind structure, J. Geophys. Res., 112, A03304, doi:10.1029/2006JA011895, 2007.

Stockwell, R., Taylor, M. J., Nielsen, K., and Jarvis, M. A.: A novel joint space-wavenumber analysis of an unusual Antarctic gravity wave event, Geophys. Res. Lett., 33, L08805, doi:10.1029/2005GL025660, 2006.

Stockwell, R., Taylor, M., Nielsen, K., and Jarvis, M.: The Evolution of a Breaking Mesospheric Bore Wave Packet, J. Geophys. Res., 116, D19102, doi:10.1029/2010JD015321, 2011.
Taylor, M. J., Turnbull, D. N., and Lowe, R. P.: Spectrometric and imaging measurements of a spectacular gravity wave event observed during the ALOHA-93 campaign, Geophys. Res. Lett., 20, 2849-2852, 1995.

Torrence, C. and Compo, G. P.: A practical guide to wavelet analysis, B. Am. Meteorol. Soc., 79, 61-78, 1998. 